\title{
Study on Innovation of Smart Library Service Model in the Era of Big Data
}

\author{
Jian RUAN ${ }^{a}$ and Sheng-Bin WANG ${ }^{b^{*}}$ \\ Library, Beihua University, Jilin, China \\ a383092240@qq.com, b8575789@qq.com \\ ${ }^{*}$ Corresponding author
}

Keywords: Big data; innovation; library service model; smart library

\begin{abstract}
Big data opens a new era of library transformation. Intelligent services of the smart library built by the big data are the innovation orientation of library service model. In the era of big data, the library should take a rational perspective to the maintenance and development of the library system, so that which can enhance the application of big data in the library, strengthen the humanistic care and promote pertinence and individuation of the smart library services, which will provide smart public services.
\end{abstract}

\section{Introduction}

Premier Li Keqiang pointed out: "In the era of big data, innovative service management platforms set up by the state should catch up with and surpass the world in big data technology applications, which will lead rapid development in all walks of life in China, that is big data research and application will be the frontier task of all walks of life to become China's" innovation, competition and development of productive forces" [1]. Now, whether it is consulting companies or government, scientific research institutions, or the mainstream media and authoritative scientific publications, it can be said to be more concerned about the study of data intensive areas.

\section{Conception and Essence of "Big Data"}

First of all, "Big Data" is a technical conception, its essential is a new technology group, which is a development model of "disruptive innovation" technology group, including data acquisition, data storage, data transmission, data processing and analysis technology, from the technology value chain, we can see the rise and development network, cloud computing and next generation internet and communication technology in areas are rapid development, the new generation of information technology industry is closely related with "Big Data", even fusion each other which is shown in Fig.1.

Secondly, the essence of "Big Data"refers to all of "digital content", but the present or future"Big Data Technology" can transform all digital content to "Data Content". Due to the development of technology, digital "elementary unit of contents"-“data" is fairly wide and rich conception which not only refers to the traditional structured data (such as digital, digital type), but also includes a large number of unstructured data, text, audio, video, especially as the technology development of sensor, networking, internet, such as the human body movement and social behavior, the state of the object and trajectory, these objects can be used as a "Data Content " to handle analysis. More importantly, through the automatic processing of data content, you can make the machine intelligent, so that people's life become more intelligent. Therefore, the content truly presented by "Big data" is the king of logic. 


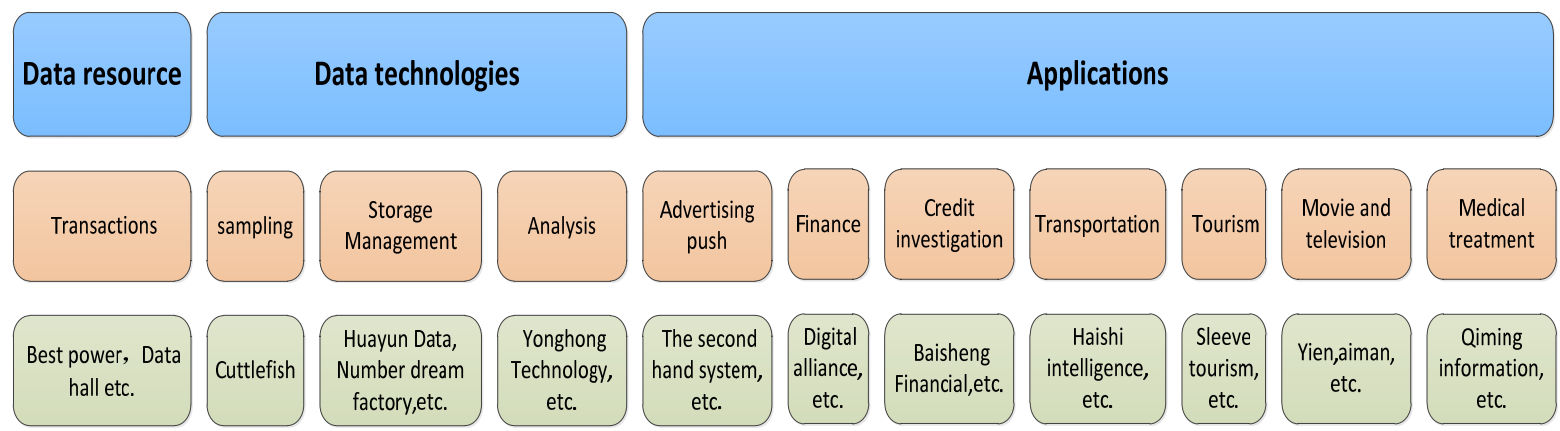

Fig.1. Big data constitute

Thirdly, the so-called big data era is a new stage of human information, due to the development and application of big data technology have been promoted to a new level, human information enter a new stage: advanced technology represented by information and communication technology, data automation and intelligent process of information content as the basic unit has begun to assist human, the information content of these only quality is valuable, but it is worthy of collection, storage and analysis of mining. "Big data era" is a "intelligent era" of "data driven" [2], from scientific research to industry technology innovation, from enterprise management to public management, from city management to business model innovation, almost every field of human society will be change of "big data", and the direction of this kind of change is "intelligence".

\section{Influence and challenge of big data to the wisdom of Library Services}

The essence of "big data" display with $4 \mathrm{~V}$ characteristics, namely, amount of data(volume), variety of data type(variety), fast of data transfer and dynamic data system (velocity)and huge of data value(value), which is illustrated Fig.2 [2].

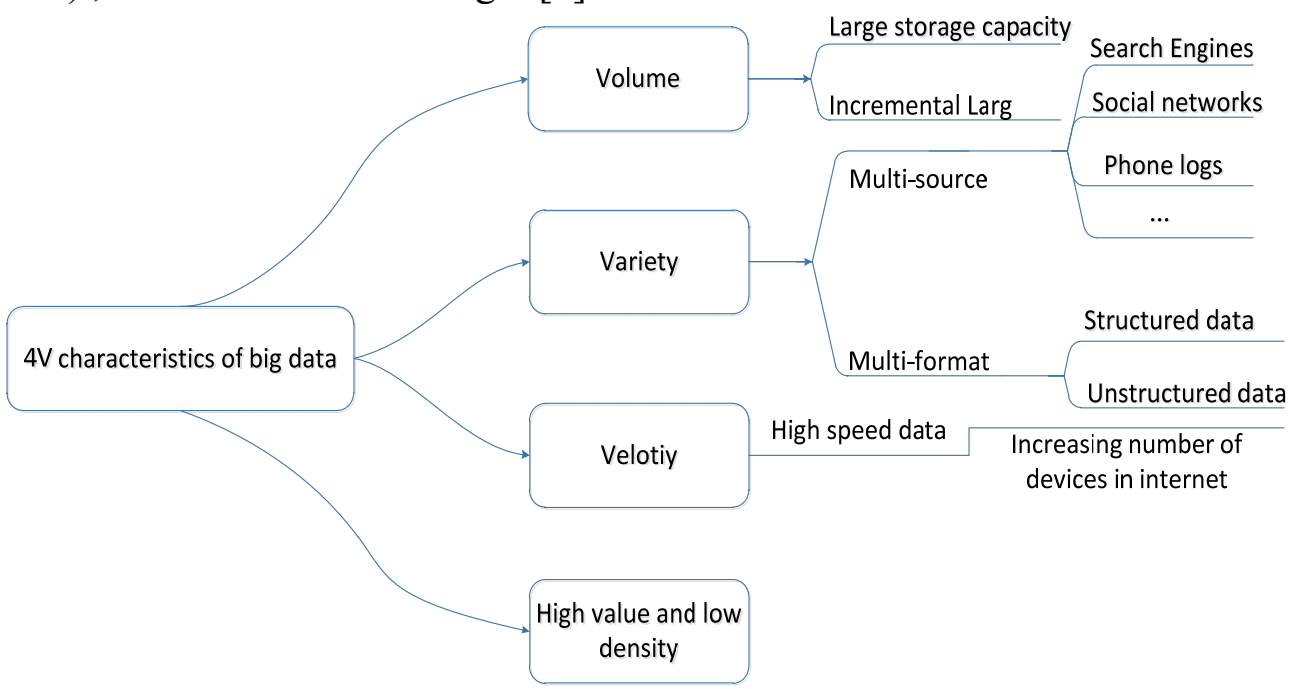

Fig.2. $4 \mathrm{~V}$ characteristics of big data

Big data will change the current information technology architecture, moreover data analysis in the data object, have a lot in common with library that use of technology、 value orientation, these will have a huge change in this era.

Firstly, improve the service quality of "big data"of intelligent library. in the Era of Big Data, the competition of library is not only the library resources, building space and service level, one of the key indicators of competition is a large amount of data and types of data mining and analysis capabilities, the development strategy of library development will depend on the analysis and forecast data.

Secondly, "big data" will become the core assets of library. With the understanding of the value of "big data", the same industry for "big data" analysis technology, these big data will be more and more valuable, such as a large number of readers' habits, the trace of service consumption, these "big data" 
will be the core asset library in the future for the development of library service patterns, trend analysis, forecast and supports.

Thirdly, "big data" processing bring opportunities and challenges of the library. Big data requires the library not only need to understand customers now enjoy library services through structured data items also need to mine and analyze occurrence of events in a lot of unstructured data, semi-structured data in the library user service in the relationship between, and to predict what will happen in the future, to find the crisis the library may face, for this reason, service marketing the model should be formulated to better deal with the unknown challenge.

\section{The Wisdom Services Oriented Oode Innovation of Library in the Ara of Big Data}

\subsection{Implement infrastructure interconnect、coalesce and sharing library}

Library needs to provide intelligent services, this services is everywhere, is the public intelligence service cooperation, it needs to be put network, database, objects, and readers' interactive elements integration as a whole in a unified smart grid, for effectively mining , integration and use a variety of interactive elements, produce large amounts of structured, semi-structured and unstructured data, which is the foundation of achieving the goal. "Big data" provides a new opportunity to the development of the library, these relevant applications and user consultation of "big data", to upgrade data for massive database service system, to develop to strengthen the theme information of the related data and quality, through collection and processing of the massive data, acquire knowledge and insight, improve the ability of the library service. From the quality of the data analysis, will usher in a data management, intelligent data services and innovation of The Times.

\subsection{Provide predictable public intelligence service}

The core of "big data" is to predict, the mathematical algorithm will be applied to predict the possibility of things happen with the massive data. In addition, with the system receives more and more data, they can be intelligent enough to switch to automatically search for the best signal and mode, and to improve their [3]. The use of big data easier to capture useful information from data model, the relationship knowledge and related resources of existing structured and unstructured, in order to establish a more flexible combination of intelligent resource data; data can be analyzed user behavior, intention and business needs, knowledge application and knowledge service capability provides a possible direction of development; the future service analysis and forecast turn the research and innovation of the data to the user into an interactive knowledge service system; analysis of instant access to data, improve the real-time prediction of the needs of users[4,5,6]. These innovations based on big data, that the public wisdom of the library services into a predictable.

\subsection{Promoting wisdom service on intelligent management}

First of all, different kinds of model of knowledge service and business risk is set up. Through the analysis, prediction and intelligent aided decision technology, set up own characteristics scientific and practical risk model. Such as digital library data security risk assessment model, data resources procurement and application [3] of risk model, publishing the income and risk model, intellectual property risk assessment model, etc.

Secondly, we can speculate on the possible crisis, help book development strategies on analysis software, hardware and data resources of the library and information institutions, or the sudden fluctuations in the resources of the organization, such as intelligence, network attacks, spam filtering, fault of resources, resource service demand and resource fluctuations, etc.

Thirdly, the library and information institutions should integrate and analyze relevant data, such as large flow, dynamic data, data association and social network data model of weibo and SMS and other for real-time data analysis and dynamic integration, discover valuable knowledge into the development environment of Library mode. The reader needs to enhance the wisdom of public service intelligent management. 


\section{Promoting Target and Personalization of The Smart library Service in The big Data Era}

\subsection{Enhance the effect of improving reading promotion service}

At present, there are many problems in the library reading promotion, especially in the aspect of sustainability and effectiveness [7,8]. The library can through extensive data analysis, such as analysis of various types of books, publishing information, social network site data, identify and understand the specific period, knowledge needs of specific groups, reading focus on positive, innovation methods of reading promotion work. That can be carried out the reading promotion not only on the surface, but also point to the point. For example, through the collection and analysis of semi-structured and non-structured data about borrowing, life experience, work for readers and so on, a comprehensive grasp of the reader's reading habits and knowledge requirements, to carry out targeted book recommendations, knowledge push work, improve the reading promotion effect.

\subsection{Improve the efficiency of community library, mobile library and so on.}

Research shows that the important reason of the low utilization library in current is that the library is too far away from the user, when the library and the user to maintain appropriate distance, can effectively promote the use of public libraries. Community library, mobile library is the effective carrier of the library users, close to the user, is the library service "nerve endings", expand the scope of the library radiation, which can solve this problem $[9,10]$. Now, many community libraries, mobile library are not based on the needs of users, targeted for the distribution of books, not in a timely manner to update the books. Big data of the era, it is through the data analysis, to grasp the specific regional population structure, accurately grasp the service time, content, form and place, greatly improve the utilization of books, play the role of the library.

\subsection{Create a comfortable and friendly library physical space}

The function of library as a data storage has been gradually reduced, the library has become a "relaxed and pleasant space", in addition to the completion of the main purpose of information search, you can also learn, office, conference, friends, visit, experience and appreciate, even date, and rest, it will become the main object of Library development[11,12]. In the era of big data, improve the rationality of library information, on the line, reading books, data association, customs and other aspects of data mining, to let the readers into the library, dig out the potential value judgment, to optimize combine the distribution of books and data display mode, in order to improve the utilization rate of materials, readers can search etc.. On the space of layout, data collection with comfort, aesthetic, light and others, combination for furniture and equipment can be extended to optimization, mobility and experience, let the reader to enjoy the experience of art information.

\section{Conclusions}

The smart library service is the core value and significance of the library in the era of big data, which has injected new vitality and strength into the development of the society, which is the technical progress of library service. For many years, the library service can always catch the opportunity to develop and satisfied the growing cultural needs of users. The library in the era of big data should promote the application of big data in the library in order to maintain the development of the library, and with the rational thinking to strengthen the wisdom of library construction, to meet the opportunities and challenges bring about "big data", to create a new world.

\section{Acknowledgement}

This research was financially supported by 2016 Jilin Provincial Social Science Project, China (Grant No.PS 1641-4). 


\section{References}

[1] Guangjian LI, Bolin HUA. Analysis of the relationship between big data analysis and information analysis [ J] Journal of China Library, 2014 (5): 14-22.

[2] Chao CHEN.Smart city: Wisdom from the big data [N]. Wen hui bao, 2012 (5):9.

[3] Maier - Schoen Berg, the era of big data. Ku Keye [M]. Sheng Yangyan, Zhou Tao, trans. Hangzhou: Zhejiang people's publishing house, 2013

[4] Cuifeng han.The impact and challenges of big data to the library. Books and information, 2012 (5): 3738 .

[5] Yuzhao Shu. Improve the custom Web log method of personalized recommendation accuracy. Books and information, 2011 (5): 6670.

[6] Aittola M, et al.Smart Library : Location-Aware MobileLibrary Service[J].International Symposium on Human Computer Interaction with Mobile Devices and Ser-vices, 2003 (5) : 411-415.

[7] Miller, et al.Smart Libraries : Best SQE Practices for Libraries with an Emphasis on Scientific Computing [EB/OL].[2013-08-29].http : //e-reports-ext.1lnl.gov/pdf/314914.pdf.

[8] http : //zh.wikipedia.org/wiki/\% E5\% A4\% A7\% E6\% 95\% B0\%E6\%8D\%AE.

[9] What is big data?[EB/OL].[2013-8-29].http//www-.ibm.com/software/data/bigdata/.Jeffrey F. Rayport.

[10]What Big Data Needs : A Code of Ethical Practices[EB/OL].[2013-8-29].http : //www.tech nologyreview.com/news/424104/what-big-data-needs-a-code-of-ethical-practices/.

[11]Jim G. On eScience : transformed scientific method[C].

[12] Tony H, Stewart T, Kirstin T. The fourth need paradigm : Data-intensive scientific discovery. Redmond, WA : Microsoft Research, 2009 : 19-33. 